\title{
The effect of different exposure parameters on proximal caries detection using the Kodak 9000 3D CBCT system
}

\author{
Efeito de diferentes parâmetros de exposição na detecção de cáries proximais usando o sistema Kodak 9000 3D \\ TCFC
}

\author{
Amanda Katarinny Goes GONZAGA' \\ Larissa Rangel PEIXOTO² \\ Luciana Soares de Andrade Freitas OLIVEIRA ${ }^{3}$ \\ Saulo Leonardo Sousa MELO ${ }^{4}$ \\ Paulo Sérgio Flores CAMPOS \\ Daniela Pita de MELO²
}

\section{ABSTRACT}

Objective

The objective of study was to evaluate the diagnostic quality of CBCT images for caries lesions detection using different exposure parameters.

\section{Methods}

Sixty extracted human teeth were selected and scanned using Kodak $90003 D C B C T$ system, with the following exposure parameters combinations: $74 \mathrm{kV}, 10 \mathrm{~mA} ; 74 \mathrm{kV}, 12 \mathrm{~mA} ; 74 \mathrm{kV}, 8 \mathrm{~mA} ; 70 \mathrm{kV}, 10 \mathrm{~mA} ; 70 \mathrm{kV}, 12 \mathrm{~mA} ; 70 \mathrm{kV}$ e $8 \mathrm{~mA} ; 70 \mathrm{kV}, 6.3 \mathrm{~mA}$. Two observers evaluated the images for caries presence using CS 3D Imaging Software. Each observer scored the proximal surfaces of each tooth on a 5-point scale. The scores were compared to histological sections used as gold standard. Accuracy for caries lesion detection was assessed for each exposure parameter combination and evaluated by means of ROC curve analysis.

\section{Results}

The mean values for the areas under the ROC curves for each exposure parameter combination varied from 0.35 to 0.60 . There was no statistical significant difference among protocols 1, 2, 4, 6 and 7. However, protocols 3 and 5 differed from all protocols.

\section{Conclusion}

Although the highest dose protocol was the most efficient for proximal caries detection, the lowest dose protocol should be chosen based on the ALADA principle.

Indexing terms: Dental caries. Radiation dosage. Radiography, dental. Tomography, x-ray computed.

\section{RESUMO}

Objetivo

Avaliar a qualidade de diagnóstico de imagens de TCFC para detecção de lesões de cárie utilizando parâmetros de exposição diferentes.

\section{Métodos}

Sessenta dentes humanos extraídos foram selecionados e digitalizados usando o sistema Kodak 9000 3D TCFC, com as seguintes combinações de parâmetros de exposição: 74 kV, 10 mA; 74 kV, 12 mA; 74 kV, 8 mA70 kV, 10 mA; 70 kV, 12 mA; 70 kV e 8 mA; 70 kV, 6,3 mA. Dois observadores avaliaram as imagens para a presença de cárie utilizando o CS 3D Imaging Software. Cada observador pontuou as superfícies proximais de cada dente em uma escala de 5 pontos. Os escores foram comparados com cortes histológicos, utilizados como padrão-ouro. A precisão para detecção de lesões de cárie foi analisada para cada combinação de parâmetros de exposição e avaliada por meio de análise da curva ROC.

\section{Resultados}

Os valores médios para as áreas sob as curvas ROC para cada combinação de parâmetro de exposição variou de 0,35-0,60. Não houve diferença estatística significativa entre os protocolos 1, 2, 4, 6 e 7. No entanto, os protocolos 3 e 5 diferem de todos os protocolos.

\section{Conclusão}

Embora o protocolo de dose mais elevada foi o mais eficiente para a detecção da cárie proximal, o protocolo de dose mais baixa deverá ser escolhido com base no princípio ALADA.

Termos de indexação: Cárie dentária. Dose de radiação. Radiografia dentária. Tomografia Computadorizada por Raios X.

\footnotetext{
${ }^{1}$ Universidade Federal do Rio Grande do Norte, Departamento de Patologia Oral. Natal, Brasil.

${ }^{2}$ Universidade Estadual da Paraíba, Departamento de Diagnóstico Oral. Rua Baraúnas, 351, Bairro Universitário, 58429-500, Campina Grande, PB, Brasil. Correspondencia para / Correspondence to: DP MELO. E-mail: <danipita@gmail.com>.

${ }^{3}$ Instituto Federal de Educação, Ciência e Tecnologia da Bahia, Departamento Acadêmico de Tecnologia em Saúde e Radiologia. Salvador, BA, Brasil.

${ }^{4}$ Universidade de Iowa, Departamento de Patologia Oral, Radiologia e Medicina. Iowa, EUA.

${ }^{5}$ Universidade Federal da Bahia, Departamento de Diagnóstico Oral, Divisão Radiologia Oral. Salvador, BA, Brasil.
} 


\section{INTRODUCTION}

Early proximal caries diagnosis still is a challenge for dental professionals. The main difficulty attributed to caries clinical detection is its proximal localization, usually in between the cervical and vestibular surfaces closer to the contact point. Those lesions are only visualized clinically when a great extension of the proximal surface is compromised ${ }^{1}$.

Proximal caries exam demands higher clinical attention, and should be done in association with complementary exams, so information on its presence and characteristics can be obtained. Although interproximal radiography is the technique of choice to complement proximal caries diagnosis, lesions in early stages to cavity formoften cannot be detected by this image modality. Aiming to increase the precise diagnosis of proximal caries lesions, especially in its early stages, new methods have been constantly proposed and tested to facilitate the precise identification of those lesions ${ }^{2}$.

Cone Beam Computed Tomography (CBCT) systems were first used in dentistry in the end of last century and, since then; the indications of this threedimensional exam have expanded significantly3. One of the advantages of CBCT is its lower radiation dose when compared to Computed Tomography (CT). The absorbed dose during $C B C T$ exam is around twelve times lower than CT exam and equivalent to a complete series of periapical radiographs ${ }^{4-7}$.

It is important to emphasize that the amount of effective dose depends on exposure parameters as tube voltage $(\mathrm{kV})$ and tube current $(\mathrm{mA})$. The usage of lower $\mathrm{kV}, \mathrm{mA}$, voxel size, degree of rotation, exposure time and field of view (FOV) is a way to reduce the dosage of radiation to which the patient is exposed ${ }^{8}$. However, at the same time, $\mathrm{kV}$ and $\mathrm{mA}$ alternatives parameters can reduce image quality when compared to the images achieved using higher dosage parameters ${ }^{9}$. An agreement between accepted exposure and image quality needs to be established, using as guidance the ALADA principle: " "as low as diagnostically acceptable"10.

Although CBCT images are not recommended for the exclusive purpose of detecting caries, when the lesion is present, it should be reported during image analyses. To the best of the authors' knowledge, previous studies have been done using $C B C T$ to detect caries lesions, however none of them comparing Kodak 9000 3D (Kodak Dental Systems, Carestream Health, Rochester, NY, EUA) exposure protocols. Therefore, the aim of this study was to evaluate proximal caries detection on acquired using different exposure parameters, in order to establish a precise image acquisition protocol using as lower as possible radiation dose for a correct diagnosis and treatment planning.

\section{METHODS}

This study protocol was approved by the last author Institutional Review Board and it is in compliance with Helsinki Declaration.

Sixty extracted human teeth (12 canines, 24 premolars and 24 molars) were mounted in twelve blocks of silicone, with four test teeth ( 2 premolars and 2 molars) and one non-test tooth (canine) each. The canine tooth was only used to assure proximal contact to the first premolar. The premolars and molars had either no or little demineralization in their proximal surfaces.

Kodak 9000 3D (Kodak Dental Systems, Carestream Health, Rochester, NY, EUA) was used to obtain CBCT images of the studied sample. Kodak 9000 $3 \mathrm{D}$ permits $\mathrm{kV}$ and $\mathrm{mA}$ variations, what is not possible in most of the CBCT systems available in the market. The phantoms were fixed in a dried human mandible using utility wax and immersed in a foam box filled with water. The CBCT scanning was achieved using the following exposure parameters protocols: $1-74 \mathrm{kV}, 10 \mathrm{~mA} ; 2-74$ $\mathrm{kV}, 12 \mathrm{~mA} ; 3-74 \mathrm{kV}, 8 \mathrm{~mA} ; 4-70 \mathrm{kV}, 10 \mathrm{~mA} ; 5-70 \mathrm{kV}$, $12 \mathrm{~mA} ; 6$ - $70 \mathrm{kV}$ e $8 \mathrm{~mA} ; 7$ - $70 \mathrm{kV}, 6.3 \mathrm{~mA}$. All chosen protocols were variations of the pre-established Kodak 9000 3D parameters recommended for adults. All images were acquired using 0.100 voxel size and $5 \mathrm{~cm} \times 3.75 \mathrm{~cm}$ FOV. The volumetric acquisitions using the seven studied parameters were saved with a code corresponding to the parameter used and phantom scanned.

\section{Viewing sessions}

Prior to all examination sessions, verbal and practical instructions and calibration tests were performed. Twelve DVDs with 7 acquisitions in random order each were handed to the observers. The images were visualized using CS 3D Imaging Software (Kodak Dental Systems, Carestream Health, Rochester, NY, EUA), displayed in a Sony VAIO (SVS151C1SX Intelcore i7, Windows 8) laptop with a 17.3-inch color monitor placed in a quiet room with dimmed light.

A maximum of seven acquisitions were evaluated per day. To avoid fatigue, a minimum of $24 \mathrm{~h}$ interval 
between each evaluation was established. Each proximal surface was evaluated separately. A total of 1344 evaluations were done.

The presence of proximal caries lesions was scored on a 5 -point confidence scale: 1 = definitely not present, 2 $=$ probably not present, $3=$ unsure, $4=$ probably present, and $5=$ definitely present.

For validating the presence of true caries, the teeth were individually embedded in acrylic (Vipcril, Vipi, São Paulo, Brazil) and serially sectioned into 100- $\mu \mathrm{m}$ thick sections in the mesiodistal direction, using a $200 \mu \mathrm{m}$ diamond band. The tooth sections were cleaned of dust and glued to microscope slides using transparent varnish. Histological validation was performed by 2 observers using a light microscope at 12.5-20X magnification. Caries were defined as present when an opaque-white demineralization or brown discoloration was observed on the surface. For validation, the observers individually assessed the teeth. If the observers' ratings varied, they were asked to perform a joint assessment to establish agreement. For the histological surface, the following scale was applied: $0=$ sound; 1 = caries in enamel; and $2=$ caries in dentine.

\section{Data analysis}

To evaluate the accuracy the CBCT images acquired using different exposure parameters, the means areas under the ROC (Receiver Operating Characteristic) curve for each exposure parameter protocol were compared by ANOVA test using the appropriate model for experiments in block, were the observers were taken as blocks and the exposure parameters as the principle factor to be evaluated.

\section{RESULTS}

Of the 96 microscopically evaluated surfaces, 63 (65\%) were shown to be healthy, 33 (35\%) presented caries lesions in enamel.

The mean ROC curve areas varied from 0.35 to 0.60. Protocols 1 (74 kV, 10mA), 2 (74 kV, 12mA), 4 (70 $\mathrm{kV}, 10 \mathrm{~mA}), 6(70 \mathrm{kV}, 8 \mathrm{~mA})$ and $7(70 \mathrm{kV}, 6.3 \mathrm{~mA})$, and did not differ statistically from each other. However, protocols $3(74 \mathrm{kV}, 8 \mathrm{~mA})$ and $5(70 \mathrm{kV}, 12 \mathrm{~mA})$ differed from all protocols, but did not differ statistically from each other $(p=0.05)$.

Protocol 1 (74 kV, 10mA) presented the higher mean ROC curve area (0.60) for caries detection in this studied sample, demonstrating that the best results were for protocols with higher exposures doses.

\section{DISCUSSION}

CBCT has a significant importance on lesion diagnosis and determination of its size, localization and involved structures of the oral maxillofacial complex. Studies in the field report that the images obtained using $\mathrm{CBCT}$ systems have higher diagnostic accuracy and sharpness ${ }^{3,11}$.

An ideal method for caries detection should present high accuracy and allow the detection of initial demineralization, therefore, CBCT systems have some advantages when compared to bitewing radiography. Since one can assess one slice of tissue at a time in CBCT images, the low contrast presented by incipient carious lesions due to the small mass differences between the surrounding sound tissues and the superimposition of those tissues can be overcome by this method ${ }^{12}$.

The advantages of CBCT when compared to conventional radiographic exams are numerous. Among those advantages, the elimination of superposition, multiplanar reconstruction, high resolution due to its high image contrast and three-dimensional visualization of the structure of interest stand out from other modalities of radiographic exams ${ }^{3-7}$. The small and isotropic voxels of the CBCT images contribute to the achievement of images with higher details, sharpness, and high definition; although a smaller voxel size can be related to higher exposure time and higher tube current, demanding higher radiation doses than intraoral radiography ${ }^{13-14}$.

Torres et al. ${ }^{15}$ reported that when exposure parameters, as exposure time, $\mathrm{kV}$ and $\mathrm{mA}$, are not altered according to voxel size, the alteration of the voxel size isolated does not interfere significantly on radiation dose. However, established CBCT parameter protocols associate small voxel size to higher exposure time and $\mathrm{mA}$, what invariably lead to the emission of higher radiation doses. CBCT radiation dose is considerably superior in comparison to the radiation doses of conventional radiographic techniques ${ }^{7}$. Therefore, Valizadeh et al. ${ }^{11}$ consider the use of $C B C T$ as a clinical routine exam impracticable.

Kodak 9000 3D CBCT due to its variable $\mathrm{kV}$ and $\mathrm{mA}$, permits the operator to lower the radiation dose to which the patients will be exposed during image acquisition according to their size and physical type. As the $k V p$ increases, so does the $X$-ray energy, the flux emitted by the tube, the $X$-ray penetrability and the number of $\mathrm{X}$-ray photons that reach the detector. When 
lowering $\mathrm{kVp}$ and $\mathrm{mA}$ parameters, the effective radiation dose is also reduced9. Radiation doses can vary according to the commercial brand of the equipment, and technical specifications used during image scanning ${ }^{16}$.

Previous studies suggested that CBCT images could be applied to different areas of dentistry, including caries detection, due to its images possibility of visualizing the dental structure in different image planes ${ }^{3-6}$. Authors diverge on the superiority of $\mathrm{CBCT}$ images against conventional radiographic images for the detection of caries lesions, especially interproximal images. According to Haiter-Neto et al. ${ }^{17}$ and Young et al. ${ }^{18}$, CBCT and digital radiographic images fail to detect incipient enamel caries lesions, as both methods present low sensibility values Charuakkra et al. ${ }^{3}$ and Valizadeh et al. ${ }^{11}$ evaluated the CBCT accuracy on proximal caries detection and compared its results to conventional radiographs. Although those studies had similar aims, their conclusions were different.

Charuakkra et al. ${ }^{3}$ evaluated secondary caries detection using two CBCT systems (Pax-500ECT e Promax 3D) to a conventional radiographic system. Pax500ECT images were acquired using $85 \mathrm{kVand} 3.5 \mathrm{~mA}$, and Promax 3D system using $84 \mathrm{kVand} 4 \mathrm{~mA}$. The results showed higher accuracy for the CBCT images $(A z=0.995$ and 0.978 , respectively) than conventional radiographs (Az 0.882) on secondary caries lesions detection. The high Az values found in this study are justified by the fact that the sample was composed by artificially prepared secondary proximal caries. The authors also state that more researches are needed to evaluate the application of CBCT for caries detection.

Valizadeh et al. ${ }^{11}$ evaluated radiographic images (65kVp, 10mA) and CBCT images (110kVp, 1.98mA) and found $A z$ values of 0.432 for conventional radiography and 0.568 for $C B C T$ for proximal caries detection. The authors concluded that the $\mathrm{CBCT}$ images did not increase caries detection accuracy compared to conventional technique. Therefore, taking in consideration $C B C T s$ high radiation dose, this technique should not be recommended if caries detection is the only diagnostic purpose of this image. Those results may be explained by the lack of experience of the observers on CBCT images or even on their higher qualification on conventional image interpretation.

In Charuakkra et al. ${ }^{3}$ study, all acquisitions were made using lower $\mathrm{mA}$ values than the ones used in this study. According to Jaju \& Jaju ${ }^{10}$, a reduction on tube current is a practical way to reduce radiation dose, but any reduction on tube current should be carefully considered, as this reduction can cause noise increase on the final image, what can reflect on diagnostic accuracy.

Wenzel et al. ${ }^{6}$ also compared CBCT images (3D AccuitomoFPD80, Morita) to two digital radiographic systems (Digora Optime, Soredex; Digora Toto, Soredex) on proximal lesions detection. All images were obtained using $65 \mathrm{kV}$ and $10 \mathrm{~mA}$. The results showed a significant improvement in the detection of proximal caries by CBCT images. However, other studies compared digital intraoral radiographs and $C B C T$ images and concluded that the use of CBCT did not increase the accuracy of proximal caries detection ${ }^{19-21}$.

Zhang et al. ${ }^{19}$ evaluated two CBCT systems (Promax 3D eKodak90003D), a PSP system and radiographic film on proximal caries detection. Kodak 9000 3D was operated using $70 \mathrm{kV}$ and $10 \mathrm{~mA}$, what corresponded to the protocol 4 used in this study. Promax 3D system was operated using $76 \mathrm{kV}$ and $6 \mathrm{~mA}$, and the PSP and radiographic film images were acquired using $70 \mathrm{kV}$ and $6 \mathrm{~mA}$. Their results showed that CBCT images presented a slightly higher efficiency on caries detection with Azs of 0.528 for Promax 3D and 0.525 for Kodak 9000 3D, but there was no statistical difference from the other studied modalities. In this study, the protocol 4, the same used on Zhang et al. ${ }^{19}$, showed one of the best results for proximal caries detection.

Radiation dose and image quality must always be part of the process when deciding which image acquisition protocol should be established. Aside from the benefits of $C B C T$ image, this system has a relatively high exposure dose. According to SEDENTEXCT22, an intraoral radiographic image has less than $1.5 \mu S v$ effective dose, while a small Field of View (FOV) CBCT acquisition varies from 11 to $674 \mu \mathrm{Sv}$. It is important to emphasize the ALADA principle, and the chosen protocol should be adapted to each specific usage ${ }^{10}$. The permitted variation on $\mathrm{kV}$ and $\mathrm{mA}$ in Kodak 9000 3D system can interfere considerably on image quality when detecting proximal caries lesions.

\section{CONCLUSION}

In this study, the studied protocol that used 74 $\mathrm{kV}$ and $10 \mathrm{~mA}$ presented higher results for proximal caries detection. Although the highest dose protocol was the most efficient for proximal caries detection, the lowest dose protocol should be chosen based on the ALADA 
principle since they did not differ statistically. New studies should be done evaluating the effect of $\mathrm{kV}$ and $\mathrm{mA}$ using other CBCT systems available in the market.

\section{Collaborators}

AKG GONZAGA, research planning; acquisition of images; writing of the article; approval of the final version of the article. LR PEIXOTO, acquisition of images;

\section{REFERENCES}

1. Demarco FF, Corrêa MB, Cenci MS, Moraes RR, Opdam NJ Longevity of posterior composite restorations: not only a matter of materials. Dent Mater. 2012;28:87-101. doi: 10.1016/j. dental.2011.09.003

2. Gordan VV, Riley JL, Carvalho RM, Snyder J, Sanderson JL, Anderson $\mathrm{M}$, et al. Methods used by dental practice-based research network (DPBRN) dentists to diagnose dental caries. Oper Dent. 2011;36:2-11. doi: 10.2341/10-137-CR

3. Charuakkra A, Prapayasatok S, Janhom A, Pongsiriwet S, Verochana K, Mahasantipiya P. Diagnostic performance of cone-beam computed tomography on detection of mechanically-created artificial secondary caries. Imaging Sci Dent. 2011;41(4):143-150. doi: 10.5624/isd.2011.41.4.143

4. Kim DI, Lee UY, Park SO, Kwak DS, Han SH. Identification using frontal sinus by three-dimensional reconstruction from computed tomography. J Forensic Sci. 2013;58(1):5-12. doi: 10.1111/j.1556-4029.2012.02185.x

5. Rathore S, Tyndall D, Wright J, Everett E. Ex vivo comparison of Galileos cone beam CT and intraoral radiographs in detecting occlusal caries. Dentomaxillofac Radiol. 2012;41(6):489-493. doi: $10.1259 / \mathrm{dmfr} / 57329547$

6. Wenzel A, Hirsch E, Christensen J, Matzen LH, Scaf G, Frydenberg M. Detection of cavitated approximal surfaces using cone beam CT and intraoral receptors. Dentomaxillofac Radiol. 2013;42(1):1-5. doi: 10.1259/dmfr/39458105

7. Murat S, Kamburoglu K, Isayev A, Kursun S, Yüksel S. Visibility of artificial buccal recurrent caries under restorations using different radiographic techniques. Oper Dent. 2013;38:197207. doi: 10.2341/12-158-L

8. Jones D, Mannocci F, Andiappan M, Brown J, Patel S. The effect of alteration of the exposure parameters of a cone-beam computed tomographic scan on the diagnosis of simulated horizontal root fractures. J Endod. 2015;41:520-5. doi: 10.1016/j.joen.2014.11.022

9. Jadu FM, Hill ML, Yaffe MJ, Lam EWN. Optimization of exposure parameters for cone beam computed tomography sialography. Dento Maxillofac Radiol. 2011;40(6):362-8. doi: 10.1259/ dmfr/81159071

10. Jaju PP, Jaju SP. Cone-beam computed tomography: Time to move from ALARA to ALADA. Imaging Sci Dent. 2015:45(4):2635. doi: 10.5624/isd.2015.45.4.263 writing of the article; approval of the final version of the article. LSAF OLIVEIRA, research planning; montage of phantoms; approval of the final version of the article. SLS MELO, evaluation of images; statistical analysis; approval of the final version of the article. PSF CAMPOS, evaluation of the images; approval of the final version of the article. DP MELO, research planning; evaluation of images; writing of the article; approval of the final version of the article.

11. Valizadeh S, Tavakkoli MA, Karimi Vasigh H, Azizi Z, Zarrabian T. Evaluation of cone beam computed tomography (CBCT) system: comparison with intraoral periapical radiography in proximal caries detection. J Dent Res Dent Clin Dent Prospects. 2012;6(4):1-5. doi: 10.5681/joddd.2012.001

12. Akdeniz BG, Gröndahl HG, Magnusson B. Accuracy of proximal caries depth measurements: comparison between limited cone beam computed tomography, storage phosphor and film radiography. Caries Res. 2006;40:202-7. doi: 10.1159/000092226

13. Maret D, Telmon N, Peters OA, Lepage B, Treil J, Inglèse JM, et al. Effect of voxel size on the accuracy of 3D reconstructions with cone beam CT. Dentomaxillofac Radiol. 2012;4(1):649-55. doi: $10.1259 / \mathrm{dmf} / 81804525$

14. Moshfeghi M, Tavakoli MA, Hosseini ET, Hosseini AT, Hosseini IT. Analysis of linear measurement accuracy obtained by cone beam computed tomography (CBCT-NewTom VG). Dent Res J. 2012;9:57-62. doi 10.4103/1735-3327.107941

15. Torres MGG, Campos PSF, Segundo NPN, Ribeiro M, Navarro M, Crusoé-Rebello I. Evaluation of referential dosages obtained by Cone-Beam Computed Tomography examinations acquired with different voxel sizes. Dental Press J Orthod. 2010;15:4243. doi: 10.1590/S2176-94512010000500008

16. Ludlow JB, Ivanovic M. Comparative dosimetry of dental CBCT devices and 64-slice CT for oral and maxillofacial radiology. Oral Surg Oral Med Oral Pathol Oral Radiol Endod. 2008;106:10614. doi: 10.1016/j.tripleo.2008.03.018

17. Haiter-Neto F, Wenzel A, Gotfredsen E. Diagnostic accuracy of cone beam computed tomography scans compared with intraoral image modalities for detection of caries lesions. Dento Maxillofac Radiol. 2008;37:18-22.

18. Young SM, Lee JT, Hodges RJ, Chang TL, Elashoff DA, White SC. A comparative study of high-resolution cone beam computed tomography and charge-coupled device sensors for detecting caries. Dentomaxillofac Radiol. 2009;37(1):445-51. doi: $10.1259 / \mathrm{dmfr} / 87103878$

19. Zhang ZL, Qu XM, Li G, Zhang ZY, Ma XC. The detection accuracies for proximal caries by cone-beam computerized tomography, film, and phosphor plates. Oral Surg Oral Med Oral Pathol Oral Radiol Endod. 2011;11(1):103-8. doi: 10.1016/j. tripleo.2010.06.025

20. Qu X, Li G, Zhang Z, Ma X. Detection accuracy of in vitro approximal caries by cone beam computed tomography images. Eur J Radiol. 2011;79(2):24-27. doi: 10.1016/j. 
ejrad.2009.05.063

21. Senel B, Kamburoglu K, Uçok O, Yüksel SP, Ozen T, Avsever H. Diagnostic accuracy of different imaging modalities in detection of proximal caries. Dentomaxillofac Radiol. 2010;39:501-11. doi: $10.1259 / \mathrm{dmfr} / 28628723$

22. SEDENTEXCT. Project Radiation protection: cone beam CT for dental and maxillofacial radiology: evidence-based guidelines, 2012 [cited 2016 Jan 10]. Available from: <http:// www.sedentexct.eu/content/guidelines-cbct-dental-andmaxillofacial-radiology>.

Received on: 2/12/2016

Final version resubmitted on: 27/3/2017

Approved on: 21/5/2017 